University of Nebraska - Lincoln

DigitalCommons@University of Nebraska - Lincoln

Faculty Publications, Department of Psychology

Psychology, Department of

September 2006

\title{
Decision-Making About Volitional Impairment in Sexually Violent Predators
}

Cynthia Calkins Mercado

John Jay College of Criminal Justice, cmercado@jjay.cuny.edu

Brian H. Bornstein

University of Nebraska-Lincoln, bbornstein2@unl.edu

Robert F. Schopp

University of Nebraska, Lincoln, rschopp1@unl.edu

Follow this and additional works at: https://digitalcommons.unl.edu/psychfacpub

Part of the Psychiatry and Psychology Commons

Calkins Mercado, Cynthia; Bornstein, Brian H.; and Schopp, Robert F., "Decision-Making About Volitional Impairment in Sexually Violent Predators" (2006). Faculty Publications, Department of Psychology. 167. https://digitalcommons.unl.edu/psychfacpub/167

This Article is brought to you for free and open access by the Psychology, Department of at DigitalCommons@University of Nebraska - Lincoln. It has been accepted for inclusion in Faculty Publications, Department of Psychology by an authorized administrator of DigitalCommons@University of Nebraska - Lincoln. 


\title{
Decision-Making About Volitional Impairment in Sexually Violent Predators
}

\author{
Cynthia Calkins Mercado, Department of Psychology, John Jay College of Criminal Justice, New \\ York, NY 10021, USA; Corresponding author: e-mail: cmercado@jjay.cuny.edu
}

Brian H. Bornstein, University of Nebraska-Lincoln

Robert F. Schopp, University of Nebraska-Lincoln

Published online: 2 September 2006

\begin{abstract}
The Kansas v. Hendricks (1997) decision, in which the Supreme Court authorized post-sentence civil commitment for certain sex offenders, appeared to be constitutionally legitimized by limiting the class of offenders eligible for this special form of civil commitment to those who are "unable to control" their dangerousness. Nowhere in the available record, however, did the Court elucidate what they meant by this notion of volitional impairment. This study sought to examine factors that legal professionals $(n=43)$, psychologists $(n=40)$, and mock jurors $(n=76)$ deem most relevant to a determination of sex offender volitional impairment. Participants, who were randomly assigned to a sexual predator commitment or an insanity hearing context, read a series of 16 vignettes that described a pedophilic offender and included combinations of variables hypothesized to be related to judgments of volitional impairment. Results suggested that participants, who as a group made remarkably high estimates of likelihood of future sexual violence, considered verbalization of control, history of sexual violence, and the context of the hearing as highly relevant to determinations of volitional impairment. Implications for policy and practice are explored.
\end{abstract}

Keywords: Sex offender, Sexual predator, Civil commitment, Sexual violence, Risk assessment, Control, Sex offending, Hendricks

The U.S. Supreme Court's Kansas v. Hendricks (1997) decision, allowing indeterminate civil commitment for certain sex offenders after completion of a prison sentence, reflects increasing societal concern about the problem of repeat sexual predation. Under the Kansas statute at issue, civil commitment requires that the state demonstrate that the sexual offender suffers from a "mental abnormality or personality disorder" and that this disorder renders the offender "likely to engage in repeat acts of sexual violence" (K.S.A., 1994, 59-29a02). At trial, the jury found beyond a reasonable doubt that Hendricks qualified as a sexually violent predator, based upon the facts that Hendricks "suffers from pedophilia" and "continues to harbor sexual desires toward children," which he admittedly cannot control when "stressed out" (Kansas v. Hendricks, 1997, p. 2078). 
In Hendricks (1997), the majority seemed to view the inability to control behavior as a distinctive form of mental abnormality that legitimized the commitment. The majority opinion noted that a finding of volitional impairment limits involuntary civil commitment "in that it narrows the class of persons eligible for confinement to those who are unable to control their dangerousness" (Kansas v. Hendricks, 1997, p. 2080). Justice Thomas, writing for the majority, indicated that "this admitted lack of volitional control, coupled with a prediction of future dangerousness, adequately distinguishes Hendricks from other dangerous persons who are perhaps more properly dealt with exclusively through criminal proceedings" (Kansas v. Hendricks, 1997, p. 2080). Though the Court appeared to rely largely upon Hendricks' assertion of a lack of control over behavior and prior history of sexual violence in finding that he suffered a volitional impairment, nowhere in the available record did the Court clarify what is meant by the vague notion of volitional impairment.

Should the Court be relying in part upon Hendricks' history of sexual violence, it is unclear how "inability to control" behavior is something other than criminal recidivism. Schopp (1998) comments that the fact that some individuals choose to repeatedly act upon antisocial desires provides no evidence of volitional impairment, as we have no way of differentiating those offenders who legitimately lose control from those who simply choose to violate social rules (Schopp, 1998). Moreover, relying on Hendricks' declaration of loss of control might be of questionable validity and reliability. Morse (1998) argues that such subjective feelings are not sufficient to establish that one is, in fact, out of control. Such subjective report, with the potential to be minimized or exaggerated to satisfy a legal threshold, is not a reliable or valid way to measure volitional impairment (Morse, 1998).

In Kansas v. Crane (2002) the Supreme Court clarified the ambiguity of whether Hendricks required inability to control behavior, suggesting in the majority opinion that although a complete lack of control is not required, something less than a complete lack of control is an important consideration. While the Court did not provide a clear account of what might qualify as something less than an absolute lack of control, it did note that those eligible for commitment will generally find it "particularly difficult to control their behavior" (Kansas v. Crane, 2002, p. 414). As in Hendricks, however, the Court failed to describe how the pathology manifested by Crane affected his volitional capacity.

A brief history of the insanity defense and volitional impairment

The acquittal of John Hinckley, Jr. (after the attempted assassination of former President Reagan) under the American Law Institute's (ALI) Model Penal Code insanity defense standard fueled a growing controversy about the definitional ambiguity of the notion of volitional impairment. Indeed, both the American Bar Association (ABA) (1983) and the American Psychiatric Association (APA) (1983) advocated for the abolition of the volitional prong, asserting that less consistent application of the insanity defense would result from utilizing such an imprecise standard (Melton, Petrila, Poythress, \& Slobogin, 1997). These concerns about how to operationalize volition led the APA (1983) to issue the following statement: "The line between an irresistible impulse and an impulse not resisted is probably no sharper than that between twilight and dusk..." (p. 685).

The ABA (1983) similarly criticized volitional tests by noting that there is still no valid or reliable basis for measuring capacity for or impairment of self control. Rogers (1984b) suggests that clinicians generally agree in judgments about both volitional $(\kappa$ $=.80)$ and cognitive $(\kappa=.75)$ standards and argues that political pressure, rather than empiricism, precipitated the truncating of the ALI standard (by removal of the volitional 
prong) (Rogers, 1984a). Others, however, note a lack of objective criteria on which to judge whether an impulse is truly irresistible or simply not resisted (Melton et al., 1997) and argue that litigation is often reduced to subjective moral guesswork, as we do not have an objective methodology for determining volitional impairment (Bonnie, 1984). Thus, although evaluators may make consistent attributions of volitional impairment, it remains unclear whether those attributions reflect impairment appropriate for any legal purpose.

Attempts to define volitional impairment

Schopp (1991) suggests that in a literal interpretation of volitional impairment, one lacks control over behavior if one is literally unable to direct movement (or lack of movement) through decision, while in a more flexible interpretation there are degrees to which behavior is controlled. While other legal theorists (e.g., Morse, 1994; Rachlin, Halpern, \& Portnow, 1984)have suggested factors that may be relevant to the exercise of control, these accounts can merely offer guidance as to the types of factors that courts may consider relevant. Moreover, as these frameworks have generally been developed with reference to the insanity context, their relevance to the concept of volition in the sexual predator arena appears less certain. While caselaw in the dangerous predator context gives some indication of what may be relevant to an inability to control standard (e.g., repeated misconduct despite consequences) (In re Crocker, 1997; In re Kunshier, 1995; In re Mattson, 1996), as well as what is not necessarily required for volitional impairment (e.g., literal volitional impairment) (In re Kunshier, 1995; In re Patterson, 1995), generally there is no clear articulation of what qualifies as inability to control and court opinions are, at times, contradictory in nature. For example, in Minnesota, the Linehan I (1994) and Schweninger (1994) courts considered evidence of planning and grooming to be inconsistent with a finding of lack of volitional control, while other courts found the lack of control standard met, even where an offender had engaged in grooming (In re Bieganowski, 520 N.W.2d at 530 [Minn. Ct. App. 1994]; In re Adolphson, 1995), where the offender's acts were characterized by a "fair amount of planning and deliberateness" (In re Pirkl, 531 N.W.2d at 905 [Minn. Ct. App. 1995]), and where the offender's actions were "deliberate to some degree" (In re Mayfield, No. C2-95-103 at 3 [Minn. Ct. App. 1995]).

Although there also have been attempts to operationalize the legal construct of volitional impairment (Hall, 1985; Giorgi-Guarnieri et al., 2002) and even specific guidelines developed for assessing control in the insanity context (Rogers \& Shuman, 2000), there tends to be no coherent account of how one might differentiate an actor who has veritably lost control from one who has decidedly abandoned control. Moreover, it is uncertain whether these guidelines or operationalizations are in fact consistent with how the Supreme Court is conceptualized control in Hendricks and Crane. Finally, there has been, on the whole, little empirical research exploring the construct of self-control. Most studies that have attempted an examination, however, have considered areas outside the context of sexual coercion, such as gambling, substance abuse, or eating behaviors. Whether the processes that undermine self-control in such situations are similar to those which undermine self-control with respect to sexual offenses is uncertain. Shively (2001), in a vignette study examining perceptions of self control among sexual aggressors found that alcohol consumption was the sole factor among a set of contextual variables that significantly lowered participants' ratings of self-control. Indeed, considerable physiological and neuroscience research seems to support a link between alcohol and substance use and impairment in the inhibitory and activational aspects of behavioral control (Casbon, 2005; Fillmore, Marczinski, \&Bowman, 2005; Lundqvist, 2005). Thus, while caselaw, empirical research, legal theory, and practice 
guidelines may offer some indication as to what is relevant to a determination of volitional impairment, there does not seem to be a clear conceptualization across or within these various disciplines (for a review see Mercado, Schopp, \& Bornstein, 2005). Instead, there is pervasive ambiguity and uncertainty, with clear definition of the notion rarely given.

\section{Research in the sexually violent predator context}

Little empirical research has yet explored issues directly relevant to the civil commitment of sex offenders. In a vignette study that did examine juror decision-making in the sexual predator context, Guy and Edens (2003) found that participants gave "remarkably high" ratings of sexual violence risk across all conditions of the study, with estimates ranging from 59 to $71 \%$ that the defendant would commit future acts of sexual violence if not civilly committed (p. 229). In another vignette study examining commitment decisions in the sexual predator context, Mercado, Pearce, and Schopp (2002) found that the majority of their sample $(66 \%)$ disagreed with the notion that the sexual predator described in the vignette was unable to control his conduct. Notably, however, results suggested that decisions about volitional impairment were unrelated to decisions about whether or not to commit sexual offenders.

Related research has, for example, examined the reliability of commitment criteria under Florida's SVP statute (Levenson, 2004a), reported descriptive information on the characteristics of sex offenders petitioned for commitment (Becker, Stinson, Tromp, \& Messer, 2003; Janus, 2000), and compared sex offenders recommended for release with sex offenders recommended for commitment (Levenson, 2004b). Notably, Levenson (2004b) found that evaluators recommended for commitment all of the offenders $(n=10)$ who had verbalized an intent to reoffend.

\section{Purpose of the present study}

Since the Supreme Court decided in Crane (2002) that some degree of inability to control behavior is necessary to legitimize Kansas' sexual predator commitment act, the question of ability to control behavior has become fundamental to sexual predator commitment decisions. The present study was designed to address several research questions: (1) How do four factors identified in empirical research and case law as relevant (verbalized lack of control [Hendricks, 1997], history of sexual crimes [Hendricks, 1997], offense planning [In re Adolphson, 1995, In re Bieganoswki, 1994, In re Crocker, 1997, In re Kunshier, 1995, In re Mattson, 1995, In re Mayfield, 1995, In re Patterson, 1995, In re Pirkl, 1995, In re Schweninger, 1994], and substance use [Casbon, 2005; Fillmore et al., 2005; Lundqvist, 2005; Shively, 2001]) relate to scaled and forced choice judgments of volitional impairment? (2) How do variables hypothesized to be related to judgments of volitional impairment affect judgments of mental disorder? (3) How do the variables hypothesized to be related to judgments of volitional impairment affect judgments about likelihood of future sexual violence? (4) Does context matter when making judgments about volitional impairment; that is, do evaluators consider volitional impairment differently in the SVP and insanity contexts? (5) Is there consensus on conceptions of volitional impairment across groups of legal professionals, psychologists, and mock jurors?

\section{Method}

Participants

The sample, which consisted of 159 participants comprising three groups who have a unique role with regard to the process of civilly committing sex offenders, included 43 legal 
professionals, 40 psychologists, and 76 jury-eligible undergraduates. Participants received either course credit (undergraduates) or monetary compensation of $\$ 15$ (professional groups) for their participation. Those offered monetary compensation were given a choice of receiving the money themselves or donating it to selected charitable organizations.

Legal professionals included 31 attorneys and 12 judges ( 31 male, 12 female; mean age = 44.8 years). Of the legal professionals, 41 identified their ethnicity as White, one as African American, and one as Latino American. Sixty-five percent of the legal professionals indicated that they had been in the profession for twenty years or less, while approximately $35 \%$ indicated that they had been in the profession for 21 years or more. Of the 31 attorneys, $39 \%$ reported being primarily involved in criminal defense, $3 \%$ reported being primarily involved in criminal prosecution, and 59\% indicated that their work was not primarily for the criminal defense nor criminal prosecution. Thirty-five percent of the legal professionals indicated having "little to no" professional involvement with sex offenders, while some $40 \%$ reported "occasional" involvement, $26 \%$ reported "fairly regular" involvement, and none reported "frequent" involvement.

Of the psychologists ( 25 male, 15 female; mean age $=40.7$ years $), 35$ identified their ethnicity as White, three as Latino American, one as African American, and one as "Other." Seventy-eight percent of the psychologists indicated having practiced for twenty years or less, while $23 \%$ had practiced for 21 years or more. Sixty-three percent of the psychologists reported "occasional" professional involvement with sex offenders, $25 \%$ reported "little to no" involvement, 3\% reported "fairly regular" involvement, and 10\% reported "frequent" involvement. Finally, $35.0 \%$ of the psychologists indicated that they worked primarily with victims of abuse and $18 \%$ reported that they worked primarily with offenders, while the largest number (48\%) indicated that their primary work was with neither offenders nor victims.

Of the jury-eligible undergraduates ( 20 male, 56 female; mean age $=23.4$ years $), 66$ identified their ethnicity as White, four as Biracial, three as African American, two as Latino American, and one as Asian/Pacific Islander.

\section{Design and procedure}

The study was a $2^{4} \times 2 \times 3$ mixed design with four types of volitional impairment either present or absent (offender verbalization, assault planning, history of pedophilic behavior, and substance abuse) among two alternate decision-making contexts (SVP or insanity hearing) and administered to three sample pools (legal professionals, psychologists, and jury-eligible undergraduates). The within-subject factors were the volitional impairment variables and the between-subject factors were context and participant sample. A website was created for the presentation of stimuli and collection of data.

The jury-eligible undergraduates were recruited from psychology classes at the University of Nebraska. The judges were recruited from a public list of all Nebraska County and District Court judges. Targeted recruitment of attorneys specializing in criminal law was facilitated through websites listing local attorneys and their practice areas (e.g., findlaw.com). It should be noted, however, that because many of the attorneys had multiple practice areas listed, the final sample included some who do not appear to do regular work in criminal matters. To maintain continuity with our legal sample, sampling of general psychologists (recruited from the Nebraska Psychological Association (NPA) through an email directory supplied by an NPA administrator) and targeted sampling of psychologists specializing in forensic practice (recruited from the American Academy of Forensic Psychology (AAFP) through an email directory supplied by an AAFP administrator) occurred. Participants were directed to the study website either by letter (judges), handouts (jury-eligible undergraduates), or email with a link (psychologists, attorneys, and judges with a listed email address). 
Upon accessing the site, all participants were randomly assigned to either the sexual predator or insanity decision-making context. Participants in the SVP condition were informed that their decisions "may help in determining whether the offender should be sent to a secure mental institution for an indefinite period of time" or "whether the offender will be released after completing his prison sentence." Alternatively, participants in the insanity context were informed that their judgments "may help in determining whether the offender should be found "not responsible by reason of insanity" or whether the offender should be deemed culpable and sent to prison. The order of the vignettes, which included all combinations of the volitional impairment variables, was completely randomized to control for carryover effects.

\section{Materials}

Participants read 16 vignettes (see Appendix) that detailed the presence or absence of each of the four hypothesized types of potential volitional impairment. For example, the presence or absence of substance abuse was suggested by a statement indicating that the offender "had been drinking heavily and using marijuana," or alternatively by a statement indicating that, "There was no evidence to show that [offender's name] had been drinking or using drugs at the time of the offense." Likewise, evidence of planning was operationalized as the offender having "carefully planned the [alleged] assault, by 'grooming' the child with candy and other indulgences and planning a time when the child's mother would not be around," or alternatively by a statement indicating that the offender "had not carefully planned the [alleged] assault" nor "coaxed the child in any manner nor planned a time when others would not be around."

Next, a statement about the offender's subjective feelings of control was included. The offender either admitted "that he is unable to control his conduct when he gets stressed out" or acknowledged "that he is able to control his conduct, even when under extreme stress." The last of the four potential volitional impairment variables was offender history. A statement indicated that the offender had either a "long history of" or "no known history of" pedophilic behavior.

Each vignette was followed by four questions, which included: (1) a Likert-type assessment of the offender's degree of volitional impairment (1: complete control over his behavior to 7: no control over his behavior), (2) a forced choice judgment of whether or not the offender has "serious difficulty" controlling behavior, (3) a forced choice judgment of whether or not the offender suffers a mental disorder, and (4) a forced choice judgment of whether or not the offender will be sexually violent in the future. Each of the forced choice questions included a Likert-type measure of confidence. While question one is relevant to Crane and Hendricks in that it asks participants to make a graded judgment about control, question two more closely mimics the actual forced choice type of judgment that seems to be required by Crane. Questions three and four also reflect the sorts of judgments these participants would be required to make in actual commitment proceedings.

\section{Results}

Overview

As the basic design of the study was a $2^{4}$ (volitional impairment variables either present or absent) by 2 (context of hearing) by 3 (sample group), the primary statistical test was a mixed analysis of variance. This same model was used for all analyses; dichotomous dependent variables were averaged across conditions. Results were analyzed through the use of descriptive statistics and a repeated measures analysis, accompanied by post hoc analyses to explore interactions. Although 
Table 1 Means for hypothesized volitional impairment variables on likert-type assessment of control over behavior $^{a}$

\begin{tabular}{llccc}
\hline Volitional impairment variables & Mean & $F$ & $p$ & $\eta^{2}$ \\
\hline Verbalized control & $3.45(1.60)$ & 109.65 & $<.001$ & .419 \\
Verbalized no control & $4.28(1.62)$ & & $<.001$ & .302 \\
History pedophilic behavior & $4.10(1.68)$ & 65.72 & .503 & .003 \\
No history pedophilic behavior & $3.63(1.49)$ & & .451 & .018 \\
Substance use & $3.89(1.54)$ & & .576 & .036 \\
No substance use & $3.84(1.59)$ & & & \\
Planned & $3.77(1.69)$ & $3.96(1.50)$ & & \\
Not Planned & & & & \\
\hline
\end{tabular}

${ }^{a}$ Numbers in parentheses are standard deviations and $d f=152$ for all analyses.

higher order interactions were included in the model, only the main effects and two-way interactions were analyzed as higher order interactions would likely be uninterpretable due to the novel and exploratory nature of this research (Stolle, Robbennolt, Patry, \& Penrod, 2002). ${ }^{1}$

\section{Likert responses regarding ability to control behavior}

With regard to the Likert-type judgments of the offender's ability to control behavior, a repeated-measures ANOVA with context and participant sample as between-subjects factors and the potential volitional impairment variables as within-subjects factors revealed that participants were significantly more likely to judge the offender to have control over his behavior when the offender had made a statement that he could control his conduct $(M=$ 3.45 ) than when the offender had made a statement that he could not control his conduct ( $M$ $=4.28$ ) (see Table 1). There was also a significant main effect for history, with the direction of the means revealing that participants judged offenders to have less control over their behavior when there was a history of pedophilic behavior $(M=4.10)$ than when there was no history of pedophilic behavior $(M=3.63)$. Further, there was a main effect for plan, with offenders viewed as having more control when the assault was planned $(M=3.77)$ than when the assault was unplanned $(M=3.96)$. There was, however, no main effect for substance use.

With regard to the between subjects variables, a main effect was found for context, $F$ (1, $152)=8.66, \eta^{2}=.054, p=.004$. When participants were told that their decisions were in the context of a SVP hearing they perceived the offender as having less control over his behavior $(M=4.18)$ than when their decisions were made in the context of an insanity hearing $(M=$ $3.50)$. There was no main effect for sample group, $F(2,152)=64.86, p=.174$

There was a significant interaction between the offender's statement regarding his subjectively assessed ability to control his own behavior and substance abuse at the time of the assault, $F(1,152)=4.26, \eta^{2}=.027, p=.041$. When offenders verbalized that they could not control their behavior, judgments about control were not dependent upon whether $(M=4.26)$ or not $(M=4.30)$ offenders had used substances, $F(1,157)=.379, \eta^{2}=.002, p=.539$, though when an offender verbalized that he could control his behavior, judgments were significantly dependent upon whether $(M=3.51)$ or not $(M=3.39)$ the offender used substances, $F(1,157)$ $=5.08, \eta^{2}=.031, p=.026$. There were no other significant two-way interactions.

\footnotetext{
${ }^{1}$ Note that although gender was not specifically hypothesized to be related to judgments in this context, an exploration of gender was undertaken given the imbalance of gender in sample groups. There were, however, no significant main effects or two-way interactions for gender.
} 
Table 2 Percentage of respondents affirming that offender has "Serious Difficulty" controlling behavior or a mental disorder or that offender will be sexually violent in the future by hypothesized volitional impairment variables ${ }^{a}$

\begin{tabular}{|c|c|c|c|c|}
\hline Variables & Percentage & $F$ & $p$ & $\eta^{2}$ \\
\hline \multicolumn{5}{|l|}{ "Serious Difficulty" } \\
\hline Verbalized control & 47.6 & 65.48 & .001 & .301 \\
\hline Verbalized no control & 68.8 & & & \\
\hline History pedophilic behavior & 65.6 & 53.90 & .001 & .262 \\
\hline No history pedophilic behavior & 51.0 & & & \\
\hline Substance use & 59.1 & 0.93 & .337 & .006 \\
\hline No substance use & 57.4 & & & \\
\hline Planned & 56.9 & 2.86 & .093 & .018 \\
\hline Not planned & 59.7 & & & \\
\hline \multicolumn{5}{|l|}{ Mental disorder } \\
\hline Verbalized control & 54.9 & 7.39 & .007 & .046 \\
\hline Verbalized no control & 59.2 & & & \\
\hline History pedophilic behavior & 67.7 & 70.58 & .001 & .317 \\
\hline No history pedophilic behavior & 46.5 & & & \\
\hline Substance use & 56.4 & 0.98 & .323 & .105 \\
\hline No substance use & 57.9 & & & \\
\hline Planned & 60.2 & 17.88 & .001 & .006 \\
\hline Not planned & 60.2 & & & \\
\hline \multicolumn{5}{|l|}{ Future sexual violence } \\
\hline Verbalized control & 82.1 & 0.92 & .339 & .006 \\
\hline Verbalized no control & 83.0 & & & \\
\hline History pedophilic behavior & 92.9 & 71.47 & .001 & .320 \\
\hline No history pedophilic behavior & 72.3 & & & \\
\hline Substance use & 81.7 & 2.19 & .141 & .014 \\
\hline No substance use & 83.4 & & & \\
\hline Planned & 88.3 & 50.07 & .001 & .248 \\
\hline Not planned & 76.9 & & & \\
\hline
\end{tabular}

${ }^{a} d f=152$ for all analyses.

Forced choice regarding whether offender has "serious difficulty" controlling behavior

When asked to make a choice regarding whether an offender has "serious difficulty" controlling his behavior, participants were more likely to make an affirmative judgment that the offender had "serious difficulty" controlling his behavior when the offender had stated that he could not control his conduct (68.8\%) than when the offender had stated that he could control his conduct (47.6\%) (see Table 2 ). There was also a significant main effect for offender history of pedophilic behavior, with participants being more likely to judge offenders as having "serious difficulty" controlling behavior when there was a history of pedophilic behavior (65.6\%) than when there was no such history $(51.0 \%)$. There were no significant main effects for substance use or planning of the offense.

With regard to the between subjects variables, a main effect was found for context, $F(1$, $152)=5.39, \eta^{2}=.034, p=.022$. When participants were informed that their decisions were in the context of a SVP hearing they were more likely to say that an offender had no control over behavior $(63.7 \%)$ than when their decisions were made in the context of an insanity hearing $(51.9 \%)$. There was no main effect for sample group, $F(2,152)=1.62, p=.202$. 
A significant interaction was found between history of pedophilic conduct and planning of the offense, $F(1,152)=3.92, \eta^{2}=.025, p=0.05$. When there was no history of pedophilic assaults, judgments about volitional impairment were not dependent upon whether $(50.9 \%)$ or not $(51.1 \%)$ offenders had planned the offense, $F(1,157)=.005, \eta^{2}=.043, p=.945$. However, when there was a history of pedophilic assaults, participants were significantly more likely to judge that the offender had difficulty controlling conduct when the offense was not planned $(68.2 \%)$ than when the offense was planned $(62.9 \%), F(1,157)=7.02, \eta^{2}$ $=.043, p=.009$. A significant interaction was also found between offender substance use and planning of the offense, $F(1,152)=4.07, \eta^{2}=.026, p=.045$. When the offender had used substances, judgments about volitional impairment were not dependent upon whether $(59.0 \%)$ or not $(59.2 \%)$ the offender had planned the act, $F(1,157)=.005, \eta^{2}=.000, p=$ .941 . However, when there was no substance use, judgments were dependent upon whether $(65.5 \%)$ or not $(60.0 \%)$ the offense was planned, $F(1,157)=7.06, \eta^{2}=.043, p=.009$.

\section{Presence of mental disorder}

With regard to judgments about the presence or absence of mental disorder, a repeated-measures ANOVA again revealed a significant main effect for offender verbalization of control, with participants being more likely to make an affirmative judgment that the offender had a mental disorder when the offender had made a statement that he could not control his conduct $(59.2 \%)$ than when the offender had made a statement that he could control his conduct (54.9\%) (see Table 2). Offenders with a history of pedophilic conduct were also significantly more likely to be judged as having a mental disorder (67.7\%) than offenders without a history of pedophilic conduct $(46.5 \%)$. Further, respondents were significantly more likely to make an affirmative judgment that the offender had a mental disorder when the offense was planned $(60.2 \%)$ than when the offense was not planned (54.0\%). There no main effect for substance use.

With regard to the between subjects variables, a main effect was found for participant group, $F(2,152)=3.15, \eta^{2}=.040, p=.046$, with psychologists being the most likely to judge that the offender had a mental disorder (63.9\%) followed by legal professionals (63.7\%) then jury-eligible undergraduates $(50.1 \%)$, though only the difference between the psychologists and jury-eligible undergraduates was significantly different, $t(1,116)=2.02$, $p=.046$. There was no main effect for context, $F(1,152)=.558, p=.456$.

There was a significant two-way interaction between history of pedophilic behavior and planning of the offense, $F(1,152)=11.19, \eta^{2}=.069, p=.001$. When the offender had a history of pedophilic behavior, judgments about mental disorder did not depend upon whether the offense was $(68.7 \%)$ or was not $(67.1 \%)$ planned, $F(1,157)=.877, \eta^{2}=.006, p=.351$. However, when the offender had no known history of pedophilic behavior, respondents were significantly more likely to judge that the offender had a mental disorder when the offense was planned $(52.0 \%)$ than when the offense was not planned $(41.0 \%), F(1,157)=25.76, \eta^{2}=.141, p=.000$.

There was also a significant interaction between participant sample and context, $F(2$, $152)=3.58, \eta^{2}=.045, p=.030$. Though a post hoc comparison did not reveal significant differences between groups in the SVP condition, psychologists in the insanity context were more likely to perceive that the offender had a mental disorder $(74.6 \%)$ than jury-eligible undergraduates $(46.6 \%$ ), with legal professionals in between. Post hoc comparisons also revealed that judges were significantly more likely to view offenders as having a mental disorder in the SVP context $(74.7 \%)$ than in the insanity context $(50.3 \%), t(1,40)=2.48$, $p=.017$, though psychologists and jury-eligible undergraduates did not show significant differences in their judgments about mental disorder across the two hearing contexts. 


\section{Likelihood of future sexual violence}

Participants were significantly more likely to make an affirmative judgment that the offender would be sexually violent in the future when the offender had a long history of pedophilic offenses $(92.9 \%)$ than when the offender had no known history of pedophilic offenses $(72.3 \%$ ) (see Table 2). There was also a significant main effect for planning of the offense, with respondents being more likely to make an affirmative judgment that the offender would be sexually violent in the future when the offense was planned $(88.3 \%)$ compared to when the offense was not planned (76.9\%). There were no significant main effects for offender verbalization of control or substance use during the crime.

With regard to the between-subjects factors, there was a significant main effect for context, $F(1,152)=5.56, \eta^{2}=.035, p=.020$, with participants being more likely to judge that the offender would be violent in the future when making the judgment in the context of an SVP hearing $(86.6 \%)$ than when making the judgment in the context of an insanity hearing $(77.8 \%)$. There was no significant main effect for participant group, $F(2,152)=.218, p=.805$. $^{2}$

There was a significant two-way interaction between the offender's statement with regard to his ability to control conduct and offense planning, $F(1,152)=5.103, \eta^{2}=.032, p=.025$. Post hoc analyses revealed that when offenders had voiced having control, judgments about future sexual violence were dependent on whether $(89.1 \%)$ or not $(75.2 \%)$ the offense was planned, $F(1,157)=57.01, \eta^{2}=.266, p=.000$. When offenders had verbalized a lack of control, judgments were also dependent on whether $(87.3 \%)$ or not $(78.6 \%)$ the offense was planned, $F(1,157)=30.10, \eta^{2}=.161, p=.000$.

There was also a significant two-way interaction between history of pedophilic offenses and offense planning, $F(1,152)=37.02, \eta^{2}=.196, p=.001$. When there was an offense history, participants were more likely to say that an offender would be sexually violent when the offense was planned $(94.8 \%)$ than when the offense was not planned $(90.9 \%)$, $F(1,157)=9.85, \eta^{2}=.059, p=.002$. When there was no history, participants were also more likely to find future sexual violence when the offense was planned $(81.8 \%)$ than when the offense was not planned $(63.0 \%), F(1,157)=61.30, \eta^{2}=.281, p=.000$.

\section{Confidence measures}

Analyses that combined the dichotomous judgments with participants' confidence ratings to create "judgment-strength" measures yielded comparable results. As decisionmakers in commitment and insanity contexts are required only to make dichotomous judgments, these judgment-strength analyses are not presented here (but are available from the first author).

\section{Discussion}

The notion of volitional impairment has long been a confused concept in the courts, with psychological and legal experts frequently noting the hollow nature of the concept. Janus (2001) commented that the concept "lacks substance" and may amount to no more than "unstructured moral guesswork" (pp. 1-2), while Schopp (2001) argues that neither the

\footnotetext{
${ }^{2}$ Despite the intention to examine only main effects and two-way interactions as per Stolle et al. (2002), all three-way interactions for sample group were also examined given the somewhat surprising lack of differences between sample groups (i.e., absence of findings). There were, however, no significant three-way interactions involving sample group. Though not presented here, these analyses are available from the first author.
} 
courts nor legislatures have "developed a normative account of volitional impairment that falls short of the clear cases such as seizure movements." (p. 246). The Association for the Treatment of Sexual Abusers (ATSA) (2001) in an amicus curiae filed in Crane notes that the volitional impairment standard is "untenable," "meaningless," and "unworkable" (p. 2). ATSA further suggests that this standard "has been largely rejected by both the medical and legal professions." If these criticisms are accurate, then the notion of volitional impairment cannot serve the discriminative function of separating those appropriate for this specialized form of commitment from those more appropriately dealt with through the criminal justice system (Hendricks, 1997). The primary goal of this study was to identify the factors that lead legal, psychological, and lay actors to make judgments of volitional impairment.

A number of key findings emerge from the results. To start, results revealed that the offender's verbalization of control (or lack thereof) is relevant to a determination of volitional impairment. Indeed, participants (both professionals and non-professionals) seemed quite willing to accept such assertions as evidence of inability to control. This finding does appear to comport with the Supreme Court's analysis in Hendricks (1997), given that the Court seemed to rely upon Hendricks' own statement that he loses control when "stressed out" (p. 2078) to support its determination that he suffered such volitional impairment. While it may seem intuitive to view an offender as lacking control when he admits just such an impairment, such testimony is, of course, of questionable validity. Indeed, given the planned, organized, and goal-directed nature of Hendricks' (and most pedophilic) assaults, there is little support for the assertion of a lack of control (Schopp, 2001, p. 28). Also problematic is that such subjective report could readily be exaggerated or minimized given an offender's desire to qualify for or avoid a particular legal status (Morse, 1998).

Decisionmakers were also more likely to conclude that an offender lacked control when there was a history of pedophilic conduct. Again, this finding seems to correspond to the Hendricks analysis, though it is somewhat perplexing given Schopp's (1998) observation that the mere fact that some individuals choose to repeatedly act upon criminal desires does not in itself provide evidence of a lack of control. Indeed, if habit or simple repetition of activities were sufficient to establish a volitional impairment, then a person who regularly engages in any criminal or non-criminal activity could be said to be volitionally impaired. Moreover, if history of pedophilic behavior provides evidence of a loss of control, then how does one differentiate the offender who veritably loses control from one with antisocial tendencies who repeatedly acts on sexual urges simply because he chooses to do so?

While the present data are less robust with regard to the importance of planning in the determination of volitional impairment, respondents were more likely to affirm difficulty controlling behavior when the offense was not planned. Intuitively, this finding makes sense, to the extent that participants viewed planning as representative of acting with forethought or intention. This less robust finding may explain the aforementioned mixed treatment that evidence of planning has received in the courts. Notably, use of substances at the time of the assault was not related to findings of volitional impairment. Because substances may impair judgment and related cognitive processes and hence the ability to regulate behavior (Casbon, 2005; Fillmore et al., 2005; Lundqvist, 2005), it is somewhat curious why participants did not view intoxication as impacting one's capacity for control. It would be valuable to investigate whether participants would have viewed "harder" drug use (e.g., cocaine), heavier alcohol and drug use, or chronic substance use differently.

Also highly relevant is the context of the hearing. Participants were more likely to view an offender as lacking control in the SVP context than in the insanity context. Because we lack an articulated description of the types of factors that should be relevant to these alternative contexts, it is somewhat difficult to evaluate these results. It is conceivable, however, that these 
alternative contexts should require different levels of volitional impairment, given the different functions and potential dispositions of these laws. Having no firm basis on which to make judgments about this ill-defined notion, participants may have framed their decisions with reference to preferred disposition. That is, participants may have been more apt to endorse a vacuous notion when it supported continued confinement over release (as in the SVP context) or incarceration over hospitalization (as in the insanity context), in line with what Pratt's (2000) suggestion of popular support for tougher measures against sex offenders.

\section{Determination of mental disorder}

Participants were significantly more likely to affirm that an offender had a mental disorder when there was acknowledgment of a lack of control. Although verbalization of lack of control has not been systematically researched and is not found as an explicit criterion in any disorders listed within the DSM-IV (APA, 1994), a number of disorders are generally associated with a failure or "inability" to resist impulses (e.g., Impulse-Control Disorders). Thus, participants may have viewed such assertions as indicative of some type of mental impairment. Participants were also considerably more likely to view an offender as having a mental disorder when there was a history of offenses. Again, insofar as respondents made decisions with regard to modern psychiatric nomenclature, the DSM-IV (APA, 1994) includes in its definition of pedophilia recurrent sexual behaviors with a child. It should be noted, however, that individuals who meet diagnostic criteria for particular psychological disorder may or may not have the specific type of impairment that qualifies them for a particular legal status (such as insanity).

Unexpectedly, decisionmakers viewed planning as relevant to a determination of mental disorder. When there was evidence of planning, participants were significantly more likely to view offenders as having a mental disorder. As psychiatric disorders common to those who assault children (e.g., Pedophilia) typically include organized, goal-directed behavior (albeit toward an objectionable end) this finding is explicable. Substance use at the time of the assault, however, was not considered relevant to a finding of mental disorder. Perhaps participants did not consider the use indicated to be suggestive of a larger pattern of dependence of the type that might qualify as a "mental disorder".

While overall there were few between group differences, the samples did show some important differences in their judgments about mental disorder. Specifically, psychologists and legal professionals showed highly comparable rates of affirming mental disorder that were considerably higher than that of the jury-eligible undergraduates, perhaps reflecting professional bias or expert knowledge.

\section{Likelihood of future sexual violence}

With regard to judgments about whether an offender is likely to be sexually violent in the future, participants considered a history of violence to be highly relevant to their decisions. Indeed, participants were far more likely to affirm that the offender would be sexually violent if the offender had a history of sexual violence. Notably, an overwhelming majority $(92.9 \%)$ judged that the offender would be sexually violent in the future when there was a history of sex crimes, and a large majority $(72.3 \%)$ also judged that the offender would be sexually violent in the future even without a history of sex crimes. Given that measures of deviant sexual interest are among the single factors most predictive of sexual recidivism (any deviant sexual interest $[d=.31]$, sexual interest in children $[d=.33]$, and paraphilic interests $[d=.21]$ ) (Hanson \& Morton-Bourgon, 2004), the importance of a history of 
sexual deviancy may at first glance seem to comport with what the research dictates. However, as mentioned, Hanson (2003) warned that no one factor is robust enough alone to be predictive of sexual violence. Moreover, Hanson and Morton-Bourgon's (2004) metaanalytic review observed a sexual offense recidivism rate of $13.7 \%$ after approximately five years. While such research likely underrepresents true rates of recidivism, Hanson (2003) notes that empirical studies rarely find sex offense recidivism rates higher than $40 \%$. Thus, participants in this sample may have overestimated the likelihood of recidivism. These overestimations are, however, consistent with those of Guy and Edens (2003).

Given that participants in this study found offense planning to be relevant to findings of future sexual violence, systematic investigation to ascertain its utility as a risk marker for sexual violence might be valuable. While offender verbalization was relevant to decisions of mental disorder and volitional control, there was no main effect of offender verbalization on determinations of future sexual violence. As noted, prior research has found that statements indicating intention to commit a future sex crime are associated with decisions about reoffense risk and recommendations for civil commitment (Levenson, 2003). Use of substances at the time of the assault was unrelated to judgments about future sexual violence. Notably, substance use is, at best, a modest predictor $(d=.12)$ of sexual recidivism (Hanson \& Morton-Bourgon, 2004). Moreover, decisionmakers were more likely to judge that the offender would be violent when they were informed that their decision was in the context of a sexual predator (as opposed to an insanity) hearing, suggesting a reliance on context rather than empirically supported risk factors.

\section{Conclusions}

Although research suggests that variations in experimental verisimilitude have little effect on mock jurors' decision (Bornstein, 1999), a limitation of this study could have been the vignette methodology. Future research might present evidence in a manner that is more realistic than the brief vignette utilized in this study to examine whether such presentation affects decision-making. Indeed, replication of this study might include, for example, presentation of expert testimony from both the prosecution and defense, video presentation of defendant testimony, and/or more thorough presentation of evidence in a trial-like format. That said, the present study is the first empirical examination of decision making about the notion of volitional impairment. Because there exists a myriad of variables which may impact judgments about volitional impairment, it would be valuable to examine in future studies how other variables (e.g., behavioral impulsivity or measures of cognitive functioning) relate to judgments about volitional impairment.

This study begins to shed light on the types of factors that legal professionals, psychologists, and jurors "count" as evidence of volitional impairment. Although it remains ambiguous what the criteria underlying the notion should be, this study provides information on the types of factors that relevant legal actors are including in their judgments (e.g., history of sexual violence, verbalization of control, context of hearing, and sometimes planning) and the types of factors that they are discounting (e.g., substance use). One of the more interesting findings is perhaps the general absence of differences among groups, suggesting that professionals and undergraduates are consistent in their consideration of factors relevant volitional impairment. This may support Morse's (2004) contention that "expert" opinion about volition is not based on any empirically grounded conceptualization of the notion but rather reflects commonsense, subjective moral opinions (that professionals and non-professionals share). Indeed, if the decisions are, in fact, based on indefensible conclusions, one must consider the ethical concern that clinicians may 
in fact be overstepping the bounds of their competence by providing pseudo-expertise about volition. Finally, this study provides the courts with information about what legal actors and mental health experts are doing in practice when it comes to making decisions about volitional impairment. This research gives the courts and legislatures an opportunity to decide whether these identified variables are those that should comprise volitional impairment, and moreover, whether they help to serve the necessary discriminative function. If they are not the types of variables that should "matter," then this suggests that the courts and legislatures need to be more explicit in articulating what the notion of volitional impairment is. They might identify, for example, how these identified factors and others support or fail to support a finding of volitional impairment.

Notably, participants in this study seemed to make decisions in a manner consistent with Hendricks. As noted above, participants were similar to the Hendricks Court in that they seemed to rely upon the offender's own assertions and history of pedophilic conduct to support determinations of volitional impairment. Despite the seeming congruence between the Court and participants in this sample, however, the issue remains as to why verbalization of lack of control and history should be indicative of volitional impairment. Even applying the less absolute "serious difficulty" standard suggested in Crane, there is still an apparent contradiction in saying that such seemingly goal-directed and organized behavior was in some manner volitionally impaired.

Given the controversial nature of this specialized form of civil commitment, it is important that commitment be predicated upon a meaningful and justifiable articulation of volitional impairment, i.e., a justificatory explanation of the concept which provides explanation for why those with control problems are suitable subjects for commitment. With knowledge about the meaning of this notion, we can begin to assess whether it serves to distinguish in a non-arbitrary manner those appropriate for only criminal justice sanction from those also eligible for civil commitment as a sexual predator.

\section{Appendix}

Vignette sample 1: All factors present

William [is currently incarcerated for having/is alleged to have] sexually assaulted a young child. At the time of the [alleged] sexual assault, William had been drinking heavily and using marijuana. Evidence revealed at trial indicated that William had carefully planned the [alleged] assault, by "grooming" the child with candy and other indulgences and planning a time when the child's mother would not be around. William admits that he is unable to control his conduct when he gets stressed out. Notably, William has a long history of pedophilic behavior.

Vignette sample 2: All factors absent

Adam [is currently incarcerated for having/is alleged to have] sexually assaulted a young child. There was no evidence to show that Adam had been drinking or using drugs at the time of the [alleged] sexual assault. Evidence revealed at trial indicated that Adam had not carefully planned the [alleged] assault, having not coaxed the child in any manner nor planned a time when others would not be around. Adam acknowledges that he is able to control his conduct, even when under extreme stress. Notably, Adam has no known history of pedophilic behavior. Psychiatric evidence also reveals that Adam shows no gross impairment in reality testing and his intelligence is within normal limits. 


\section{References}

American Bar Association. (1983). Model code of professional conduct. Chicago, IL: American Bar Association.

American Psychiatric Association. (1983). American Psychiatric Association statement on the insanity defense. American Journal of Psychiatry, 140, 681-688.

American Psychiatric Association. (1994). Diagnostic and statistical manual of mental disorders, 4th edn. Washington, DC: American Psychiatric Association.

Association for the Treatment of Sexual Abusers (ATSA) as amicus curiae in support of petitioner, Kansas $v$. Crane, 2002 WL 75609 (No. 00-957) (2001).

Becker, J. V., Stinson, J., Tromp, S., \& Messer, G. (2003). Characteristics of individuals petitioned for civil commitment. International Journal of Offender Therapy and Comparative Criminology, 47, 185-195.

Bonnie, R. J. (1984). Morality, equality, and expertise: Renegotiating the relationship between psychiatry and the criminal law. Bulletin of the American Academy of Psychiatry and Law, 12, 5-20.

Bornstein, B. H. (1999). The ecological validity of jury simulations: Is the jury still out? Law and Human Behavior, 23, 75-91.

Casbon, T. S. (2005). Drinking and cognitive control: Evidence that acute alcohol intoxication impairs performance through its effect on two distinct cognitive processes. Dissertation Abstracts International: Section B: The Sciences and Engineering, 65(12-B), 6644.

Giorgi-Guarnieri, D., Janofsky, J., Keram, E., Lawsky, S., Merideth, P., Mossman, D., et al. (2002). Practice guideline: Forensic psychiatric evaluation of defendants raising the insanity defense. The Journal of the American Academy of Psychiatry and the Law, 30 (Suppl), S3-S40.

Guy, L. S., \& Edens, J. F. (2003). Juror decision-making in a mock sexually violent predator trial: Gender differences in the impact of divergent types of expert testimony. Behavioral Sciences and the Law, 21, 123.

Hanson, R. K. (2003). Who is dangerous and when are they safe? Risk assessment with sexual offenders. In B. J. Winick \& J. Q. LaFond (Eds.), Protecting society from sexually dangerous offenders: Law, justice, and therapy (pp. 63-74). Washington, DC: American Psychological Association.

Hanson, R. K., \& Morton-Bourgon, K. (2004). Predictors of sexual recidivism: An updated meta-analysis.(User Report 2004-02). Ottawa: Public Safety and Emergency Preparedness Canada.

Hall, H. V. (1985). Cognitive and volitional capacity assessment: A proposed decision tree. American Journal of Forensic Psychology, 3, 3-17.

Fillmore, M. T., Marczinski, C. A., \& Bowman, A. M. (2005). Acute tolerance to alcohol effects on inhibitory and activational mechanisms of behavioral control. Journal of Studies on Alcohol, 66, 663-672.

In re Adolphson, No. C5-95-533 (Minn. Ct. App. July 25, 1995) (unpublished).

In re Bieganowski, 520 N.W.2d 525 (Minn. Ct. App. 1994).

In re Crocker, No. C7-97-604 (Minn. Ct. App. Aug. 19, 1997), sum. aff'd (Jan. 21, 1997) (unpublished).

In re Kunshier, No. C7-95-1490 (Minn. Ct. App. Nov. 21, 1995) (unpublished).

In re Mattson, No. C5-95-452 (Minn. Ct. App. June 20, 1995) (unpublished).

In re Mayfield, No. C2-95-103 (Minn. Ct. App. May 2, 1995) (unpublished).

In re Patterson, No. C3-95-935 (Minn. Ct. App. Sept. 19, 1995) (unpublished).

In re Pirkl, 531 N.W.2d 902 (Minn. Ct. App. 1995), rev. denied (Minn. Aug. 30, 1995).

In re Schweninger, 520 N.W.2d 446 (Minn. Ct. App. 1994), rev. denied, (Minn. Dec. 12, 1997).

Janus, E. S. (2001). Sex offender commitments and the "inability to control"-Developing legal standards and a behavioral vocabulary for an elusive concept. In A. Schlank (Ed.), The sexual predator, volume II: Legal issues, clinical issues, special populations. Kingston, NJ: Civic Research Institute.

Janus, E. S. (2000). Sex offender commitments in Minnesota: A descriptive study of second generation commitments. Behavioral Sciences and the Law, 18, 343-374. 
Kansas v. Crane, 534 U.S. 407 (2002). Kansas v. Hendricks, 117 S.Ct. 2072 (1997)

K.S.A. §59-29a02 (1994). Levenson, J. (2004a). Reliability of sexually violent predator civil commitment criteria in Florida. Law and Human Behavior, 28, 357-368.

Levenson, J. (2004b). Sexual predator civil commitment: A comparison of selected and released offenders. International Journal of Offender Therapy and Comparative Criminology, 48, 638-648.

Linehan I, 518 N.W.2d 609 (Minn. 1994).

Lundqvist, T. (2005). Cognitive consequences of cannabis use: Comparison with abuse of stimulants and heroin with regard to attention, memory and executive functions. Pharmacology, Biochemistry and Behavior, 81, 319-330.

Melton, G. B., Petrila, J., Poythress, N. G., \& Slobogin, C. (1997). Psychological evaluations for the courts: A handbook for mental health professionals and lawyers, 2nd edn. New York: Guilford Press.

Mercado, C. C., Pearce, M. W., \& Schopp, R. F. (2002, March). Hendricks and the "inability to control" dangerousness. Paper presented at the meeting of the American Psychology-Law Society, Austin, TX.

Mercado, C. C., Schopp, R. F., \& Bornstein, B. H. (2005). Evaluating sex offenders under sexually violent predator laws: How might mental health professionals conceptualize the notion of volitional impairment? Aggression and Violent Behavior, 10, 289-309.

Morse, S. J. (1994). Culpability and control. University of Pennsylvania Law Review, 142, 1587-1660.

Morse, S. J. (1998). Fear of danger, flight from culpability. Psychology, Public Policy, and Law, 4, 250-267.

Morse, S. J. (2004). Preventive confinement of dangerous offenders. Journal of Law, Medicine, and Ethics, 32, $56-72$.

Pratt, J. (2000). Sex crimes and the new punitiveness. Behavioral Sciences and the Law, 18, 135-151.

Rachlin, S., Halpern, A. L., \& Portnow, S. (1984). The volitional rule, personality disorders and the insanity defense. Psychiatric Annals, 14, 139-147.

Rogers, R. (1984a). APA's position on the insanity defense: Empiricism versus emotionalism. American Psychologist, 42, 840-848.

Rogers, R. (1984b). Rogers criminal responsibility assessment scales (RCRAS) and test manual. Odessa, FL: Psychological Assessment Resources, Inc.

Rogers, R., \& Shuman, D. W. (2000). Conducting insanity evaluations: 2nd edn. New York: The Guilford Press.

Schopp, R. F. (1991). Automatism, insanity, and the psychology of criminal responsibility: A philosophical inquiry. New York: Cambridge University Press.

Schopp, R. F. (1998). Civil commitment and sexual predators: Competence and condemnation. Psychology, Public Policy, and Law, 4, 323-376.

Schopp, R. F. (2001). Competence, condemnation, and commitment. Washington, DC: American Psychological Association.

Shively, M. (2001). Male self-control and sexual aggression. Deviant Behavior, 22, 295-301.

Stolle, D. P., Robbennolt, J. K., Patry, M., \& Penrod, S. D. (2002). Fractional factorial designs for legal psychology. Behavioral Sciences and the Law, 20, 5-17. 